\title{
QUALIDADE FISIOLÓGICA DE SEMENTE DE CAFÉ ARÁBICA NA PRESENÇA DE ALUMÍNIO ${ }^{1}$
}

\author{
CÉLIA MARIA PEIXOTO DE MACEDO², JOSÉ CARLOS LOPES ${ }^{3}$
}

\begin{abstract}
RESUMO - O objetivo deste trabalho foi avaliar a germinação e o vigor da semente da espécie Coffea arabica, cultivares Catuaí Amarelo (IAC 62), Obatã, Oeiras e IAPAR 59, na presença de alumínio. O delineamento experimental foi o inteiramente casualizado, num arranjo fatorial (4 x 2), com quatro repetições, correspondendo às quatro cultivares e as soluções sem e com alumínio na forma de $\mathrm{Al}_{2}\left(\mathrm{SO}_{4}\right)_{3} \cdot 16 \mathrm{H}_{2} \mathrm{O}$, na concentração de $45 \mathrm{mg} \cdot \mathrm{L}^{-1}$. A semente foi semeada em rolos de papeltoalha, mantidos em BOD a $30^{\circ} \mathrm{C}$, na ausência de luz. Não houve interação significativa entre as cultivares e o alumínio. Entre as quatro cultivares, a semente de Catuaí Amarelo (IAC 62) apresentou menores desempenho germinativo e vigor. A germinação da semente das cultivares de café arábica é afetada pelo $\mathrm{Al}^{3+}$ até a concentração de $45 \mathrm{mg} . \mathrm{L}^{-1}$. No entanto, nessa mesma concentração de $\mathrm{Al}^{3+}$, ocorre estimulo ao crescimento da raiz primária.
\end{abstract}

Termos para indexação: Coffea arabica, alumínio, capacidade germinativa, vigor, toxidez.

\section{PHYSIOLOGICAL QUALITY OF ARABIC COFFEE SEEDS IN THE PRESENCE OF ALUMINIUM}

\begin{abstract}
The objective of this study was to evaluate the germination and vigor of the seed of Coffea Arabica L., cultivars Catuaí Amarelo IAC 62, Obatã, Oeiras, and IAPAR 59, in the presence of aluminum. A completely random design was used with four replications, in a 4 x 2 factorial outline, corresponding to the four cultivars and the absence and presence of $\mathrm{Al}$ in the form of $\mathrm{Al}_{2}\left(\mathrm{SO}_{4}\right)_{3} \cdot 16 \mathrm{H}_{2} \mathrm{O}$, at the concentration of $45 \mathrm{mg} . \mathrm{L}^{-1}$. The seeds were placed to germinate in paper-towel, incubated at $30{ }^{\circ} \mathrm{C}$ without light. There was no significant interaction between cultivars and aluminum. Among the studied cultivars, Catuaí Amarelo (IAC 62) was found to be the one with the most sensitive seeds to aluminium. The germination of the seeds of the studied cultivars was not affected by the concentration of $45 \mathrm{mg} . \mathrm{L}^{-1}$ of $\mathrm{Al}^{3+}$. However, at that $\mathrm{Al}^{+3}$ concentration, the growth of the primary root of the four cultivars was observed to be stimulated.
\end{abstract}

Index terms: Coffea arabica, alumínium, germination, vigor, toxicity.

\section{INTRODUÇÃO}

A importância da cafeicultura brasileira pode ser visualizada pelo volume de produção, pelo consumo interno,

${ }^{1}$ Submetido em: 01/06/2007. Aceito para publicação em: 24/10/2007. Parte da dissertação de mestrado do primeiro autor, que será apresentada ao Centro de Ciências Agrárias da UFES, para obtenção do Título de Mestre em Produção Vegetal.

${ }^{2}$ Engenheira Agrônoma, aluna do Programa de Pós-graduação em Produção pela sua participação na pauta de exportação e capacidade de geração de emprego e de renda na economia (Teixeira, 2002). O café é hoje o segundo maior gerador de riquezas do planeta, perdendo apenas para o petróleo. O Brasil,

Vegetal, bolsista FAPES/CAPES, Centro de Ciências Agrárias (CCA-UFES), Cx. Postal 16, CEP 29500-000, Alegre-ES, celiampm@yahoo.com.br

${ }^{3}$ Engenheiro Agrônomo, Dr., Prof. Associado, Departamento de Produção Vegetal, CCA-UFES / Campus de Alegre, Cx. Postal 16, CEP 29500-000, Alegre-ES,jclopes@cca.ufes.br; jcufes@bol.com.br 
atualmente, é o principal exportador e responde por mais de um terço de toda a produção mundial - três vezes mais do que a Colômbia, o segundo maior exportador (CBP\&D/Café, 2004). Nos últimos anos, a redução da cota da exportação do produto provocou a necessidade de maior qualidade e redução de custos, para atender a demanda de consumidores cada vez mais exigentes (Costa e Carvalho, 2006)

NoEstado do Espírito Santo, a atividade cafeeira constituise na mais importante atividade do setor agropecuário, tanto do ponto de vista econômico como do social. Estima-se que seja, direta ou indiretamente, responsável pela geração de cerca de 550 mil empregos e chega, em determinados anos, a responder por cerca de $85 \%$ da arrecadação do setor primário estadual (Fonseca et al., 2002).

Através do Programa de Melhoramento Genético da espécie de Coffea arabica no Espírito Santo, realizado no Instituto Capixaba de Pesquisa e Extensão Rural INCAPER, e com vistas ao aumento da produtividade e à melhoria da qualidade do café arábica no Estado, Ferrão et al. (2004) indicaram como as principais cultivares para o plantio no Estado: Mundo Novo (IAC 376-4), Icatu Precoce (IAC 3282), Catuaí Vermelho (IAC 44, IAC 81, IAC 99, IAC 144), Catuaí Amarelo (IAC 62, IAC 86), Catuaí Rubi (MG 1192), Topázio MG (MG 1189, MG 1190), IAPAR 59, Katipó (245-3-7) e Oeiras (MG 6851). Dentre os materiais genéticos introduzidos e em testes, algumas cultivares de porte baixo a médio e com resistência à ferrugem, como 'Obatã', 'Tupi', 'Catucaí'e 'Paraíso', tem se destacado.

A produção de mudas de café arábica é obtida a partir de sementes retiradas de lavouras reconhecidamente produtivas ou adquiridas de centros de pesquisa (Bragança et al., 1995). Desta forma, é de fundamental importância a obtenção de sementes de café de alta qualidade fisiológica, uma vez que, a utilização de sementes sadias, de procedência conhecida e com alto desempenho germinativo tem sido considerada como os principais fatores responsáveis pela obtenção de mudas mais vigorosas em condições de campo, resultando em maiores produtividades na exploração comercial da cultura (Braccini et al, 1998a).

As sementes de café, embora incluídas, inicialmente, no grupo das sementes recalcitrantes (King e Roberts, 1979), devido à curta viabilidade, posteriormente foram incluídas em uma categoria intermediária por Ellis et al. (1990), ao verificarem que sementes de quatro cultivares de Coffea arabica não apresentaram redução significativa na germinação, quando tiveram os teores de água reduzidos a aproximadamente $10 \%$, embora tenham sido prejudicadas pelo armazenamento sob temperaturas de 0 e $20^{\circ} \mathrm{C}$. Mycock
(1995) citado por Sakiyama et al. (1999) também observou que a semente pode ser seca, mas não pode ser armazenada em temperaturas abaixo de $10^{\circ} \mathrm{C}$, o que impede a manutenção de seu poder germinativo por períodos longos. A presença do endocarpo (pergaminho) e baixas temperaturas atrasam a germinação; com a remoção do pergaminho e sob temperatura de $32^{\circ} \mathrm{C}$, as sementes maduras de cafeeiro germinam em 15 dias (Rena e Maestri, 1986). Carvalho et al. (1999) avaliando os efeitos de tratamentos aplicados nas sementes de cafeeiro com e sem pergaminho, na emergência e desenvolvimento das mudas, verificaram que a retirada manual do pergaminho contribui para acelerar o desenvolvimento das mudas de café, corroborando as afirmações de Rena e Maestri (1986). Outro fator que contribui para a lenta germinação das sementes de café é o espermoderma, possivelmente devido à presença de cafeína (Pereira, et al., 2002). Esta camada é formada por células remanescentes do tecido nucelar, que envolve todo o endosperma e persiste como células viáveis até a maturação do fruto e semente (Castro et al., 2001). Rosa et al. (2006) estudando o efeito da cafeína exógena sobre a germinação e o desenvolvimento de embriões de Coffea arabica L. e de Coffea canephora Pierre verificaram que o efeito detrimental da cafeína exógena em embriões de Coffea é maior nas radículas do que nos cotilédones, sendo os embriões de Coffea arabica L. mais sensíveis aos efeitos negativos da cafeína exógena do que embriões de Coffea canephora Pierre.

Em solos ácidos, como os silicatados e outros substratos pobres em bases, ferro e manganês estão fartamente disponíveis e compostos de alumínio são facilmente solubilizados atuando sobre o metabolismo inorgânico e sobre o vigor das plantas (Larcher, 2000). O alumínio trocável dos solos, além de interferir no desenvolvimento da planta pode reduzir a germinação de algumas espécies (Custódio et al., 2002). Na planta ele atua indiretamente no processo metabólico associado com a divisão celular, através da inibição do processo de crescimento, interferindo na replicação de DNA durante a interfase (McQuattie e Schier, 1990).

Há evidências de que o Al é transportado através da membrana plasmática da raiz para dentro das células, após uma curta exposição do tecido ao mesmo (Lazof et al., 1994), provavelmente como Al-ligante neutro, por endocitose, através das proteínas integrais da membrana, ou através de lesões causadas por estresse (Tice et al., 1992). A influência negativa do Al sobre a condutibilidade hidráulica das raízes evidencia que a membrana plasmática é o sítio primário da injúria causada pelo Al (Zhao et al., 1987). No simplasto de 
raízes de soja (Glycine max) Lazof et al. (1994) detectaram a presença de $\mathrm{Al}$ após somente 30 minutos de exposição ao mesmo, o que sugere que a entrada do Al nas células pode ocorrer antes que o crescimento da raiz esteja inibido e sugere que a toxicidade do Al no simplasto é possível.

Embora o Al não seja considerado um nutriente para os vegetais, como o manganês (Mn), ambos desempenham importante papel na nutrição das plantas cultivadas, principalmente em solos de regiões tropicais úmidas, bastante intemperizados, pois podem aparecer em concentrações tóxicas. Quando presente em elevadas concentrações o desenvolvimento do sistema radicular é afetado, aumentando o seu diâmetro e reduzindo o número das raízes absorventes, acarretando em dificuldades na absorção de nutrientes e de água pelas plantas (Mascarenhas, 2004). Muitos cátions trivalentes são tóxicos às plantas, porque a toxicidade do Al é restringida pela maior parte às circunstâncias ácidas (Delhaize e Ryan, 1995). O Al ${ }^{3+}$ é comprovadamente tóxico, assim como outros policátions (Kinraide, 1991).

Braccini et al. (1998b) verificaram que em espécies de cafeeiro pode haver diferentes níveis de tolerância em relação à presença do $\mathrm{Al}$ tóxico, quando se avaliam variáveis relacionadas ao crescimento das raízes. Entretanto, Konrad et al. (2005), estudando os efeitos do Al tóxico sobre as variáveis relacionadas com as trocas gasosas de $\mathrm{CO}_{2}$ e de $\mathrm{H}_{2} \mathrm{O}$ e fluorescência da clorofila em seis cultivares de cafeeiro, observaram que não houve diferenças importantes quanto à tolerância ao $\mathrm{Al}^{3+}$, visto que em todas elas o processo da fotossíntese foi afetado significativamente e em intensidades semelhantes.

Entre os procedimentos mais utilizados para se avaliar a divergência genética, têm-se destacado, principalmente após o desenvolvimento da informática, as seguintes técnicas: análise por componentes principais, análise por variáveis canônicas e métodos de agrupamento, cuja aplicação depende da utilização de uma medida de dissimilaridade previamente estimada. A utilização dos componentes principais é mais apropriada quando se dispõe de informações sem repetições. Já as variáveis canônicas devem ser utilizadas quando se têm informações de "r"observações de cada uma das “ $p$ " variáveis avaliadas em "n" populações, variedades, linhagens e outros (Morais et al., 1998). A análise por variáveis canônicas, quando utilizada em estudo de divergência genética, tem como propósito possibilitar a identificação de indivíduos similares em gráficos de dispersão "bi” ou tridimensionais, à semelhança dos componentes principais. A viabilidade do uso das variáveis canônicas em estudo sobre a divergência genética, em gráficos de dispersão, também está restrita à concentração da variabilidade disponível entre as primeiras variáveis (Cruz et al., 2004).

Diante do exposto, o objetivo deste trabalho foi avaliar o desempenho germinativo e o vigor de sementes de quatro cultivares da espécie Coffea arabica em presença e ausência de alumínio.

\section{MATERIAL E MÉTODOS}

Este trabalho foi conduzido no Laboratório de Tecnologia e Análise de Sementes do Departamento de Fitotecnia do Centro de Ciências Agrárias da Universidade Federal do Espírito Santo, CCA-UFES, em Alegre-ES, no período de novembro de 2005 a fevereiro de 2006. Foram utilizadas sementes das cultivares Catuaí Amarelo IAC 62, Obatã, Oeiras e IAPAR 59 da espécie Coffea arabica, provenientes do Instituto Capixaba de Pesquisa e Extensão Rural - INCAPER, Venda Nova do Imigrante - ES.

Utilizou-se o delineamento inteiramente casualizado, com quatro repetições de 50 sementes. Os tratamentos foram distribuídos no esquema fatorial $4 \times 2$, composto por quatro cultivares de café (Catuaí Amarelo IAC 62, Obatã, Oeiras e IAPAR 59) e duas soluções, uma sem e outra com $\mathrm{Al}^{3+}$ (45 mg. $\left.\mathrm{L}^{-1}\right)$ na forma de $\mathrm{Al}_{2}\left(\mathrm{SO}_{4}\right)_{3} \cdot 16 \mathrm{H}_{2} \mathrm{O}$.

A solução nutritiva foi composta de $\mathrm{MgSO}_{4} 0,1 \mathrm{mmol}$. $\mathrm{L}^{-1}$, $\mathrm{KNO}_{3}$ 0,1 mmol.L $\mathrm{L}^{-1}, \mathrm{NH}_{4} \mathrm{NO}_{3}$ 0,15 mmol.L $\mathrm{L}^{-1}$ e $\mathrm{KHC}_{8} \mathrm{H}_{4} \mathrm{O}_{8} 8,0$ mmol.L $\mathrm{L}^{-1}$ (bifitalato de potássio para manter o $\mathrm{pH}$ em torno de 4,0), mudando com relação a adição de $\mathrm{Al}^{3+}$. O pH da solução foi mantido em 4,0 (Fageria, 1998; Kinraide, 1991). As sementes foram tratadas com Captan $\left(\right.$ Orthocide $\left.^{\circledR}\right)$ a $0,1 \%$ por três minutos.

Após a retirada dos pergaminhos das sementes, estas foram submetidas às seguintes determinações em laboratório: teor de água - utilizando-se duas repetições de $5 \mathrm{~g}$ de sementes de cada cultivar, empregando-se o método da estufa $105 \pm 3^{\circ} \mathrm{C}$, por 24 horas (Brasil, 1992); teste de germinação - com quatro repetições de 50 sementes por tratamento, distribuídas entre três folhas de papel-toalha tipo Germitest $^{\circledR}$, umedecidas, na proporção de 2,5 vezes o peso do papel, com solução nutritiva em diferentes concentrações de $\mathrm{Al}^{3+}$. Os rolos de papel foram colocados na posição vertical dentro de vasos de plásticos contendo uma lâmina de solução nutritiva sem e com $\mathrm{Al}^{3+}$, de maneira a manter a base dos rolos sempre umedecida. Os recipientes foram mantidos no escuro dentro do germinador, sob temperatura constante de $30 \pm 1^{\circ} \mathrm{C}$. A porcentagem de germinação foi obtida pela avaliação realizada aos 30 dias após a semeadura, de acordo com as prescrições das Regras para Análise de Sementes 
(Brasil, 1992), considerando-se germinadas as sementes que apresentaram protrusão da raiz primária com $2 \mathrm{~mm}$ de comprimento; conjuntamente com o teste de germinação, foi avaliado o vigor das sementes pelo teste de primeira contagem de germinação(\%) - que foi obtido com base no teste de germinação, considerando a porcentagem de plântulas que, aos 15 dias após a semeadura, apresentavamse com emissão radicular; e pelo teste de comprimento de raiz $(\mathrm{cm})$ - aos 40 dias, após a semeadura no teste de germinação, o comprimento da raiz principal foi medido, com régua milimetrada.

Análise estatística - para a análise de variância, através do software SAEG 7.1, foi utilizado o teste F e as médias foram comparadas pelo teste de Tukey a 5\% de probabilidade.

Os graus de divergência genética das quatro cultivares de café arábica foram avaliados pela análise por variáveis canônicas, utilizando-se o programa GENES.

\section{RESULTADOS E DISCUSSÃO}

O teor de água das sementes para condução dos testes foi ajustado para $14 \%$. O pH da solução, onde foram umedecidas as folhas dos rolos de papel-toalha tipo Germitest ${ }^{\mathbb{}}$, foi inicialmente ajustado para 4,0, porque nesse nível de acidez aumenta-se a disponibilidade de $\mathrm{Al}^{3+}$ (Fageria, 1998; Kinraide, 1991), que é a forma tóxica.

Para todas as características avaliadas, não houve interação entre os fatores cultivares de café e o alumínio. Portanto, na Figura 1 estão agrupados os resultados da primeira contagem, da germinação total e comprimento da raiz primária das quatro cultivares de café, independente da ausência ou presença de alumínio, e na Figura 2 estão agrupados os resultados das mesmas características sob influência do alumínio independente das cultivares estudadas.

Verifica-se na Figura 1 que a diferença estatística entre as médias dos valores obtidos das cultivares, para a primeira contagem e para germinação total, foi significativa, apontando a cultivar Catuaí Amarelo IAC 62, como a de menores médias. As sementes das cultivares IAPAR 59, Obatã e Oeiras mostraram-se, portanto, mais vigorosas e com maior desempenho germinativo. Entretanto, para a característica de vigor (comprimento de raiz primária) não houve diferença significativa entre as médias das cultivares.

Enquanto na Figura 2, observa-se que as médias dos valores obtidos para a primeira contagem e para germinação total, na ausência ou presença de alumínio, não apresentaram diferença estatística significativa. Estes resultados corroboram com aqueles obtidos por Custódio et al. (2002), que estudando o comportamento de quatro cultivares de soja com relação à germinação e vigor das plântulas mantidas sob estresse ácido por alumínio ou $\mathrm{pH}$, observaram que as concentrações de alumínio estudadas não afetaram a germinação e massa seca de raiz. No entanto, observa-se ainda na Figura 2 que o tratamento com o nível de alumínio de $45 \mathrm{mg} . \mathrm{L}^{-1}$ foi o
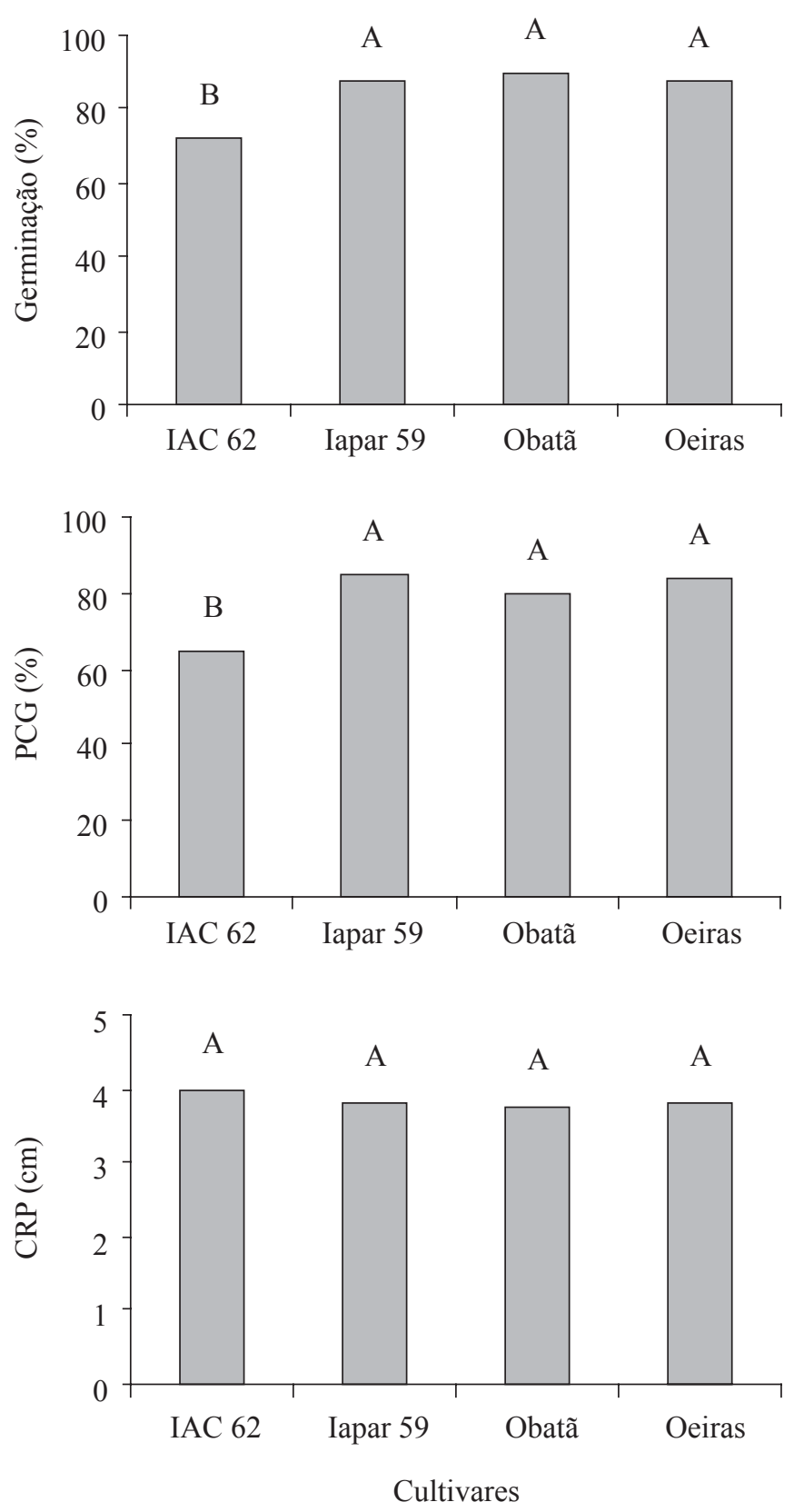

Figura 1. Germinação total, primeira contagem (PCG) de sementes e comprimento da raiz primária (CRP) de plântulas de quatro cultivares de café arábica. CCA-UFES, Alegre, ES, 2006. 

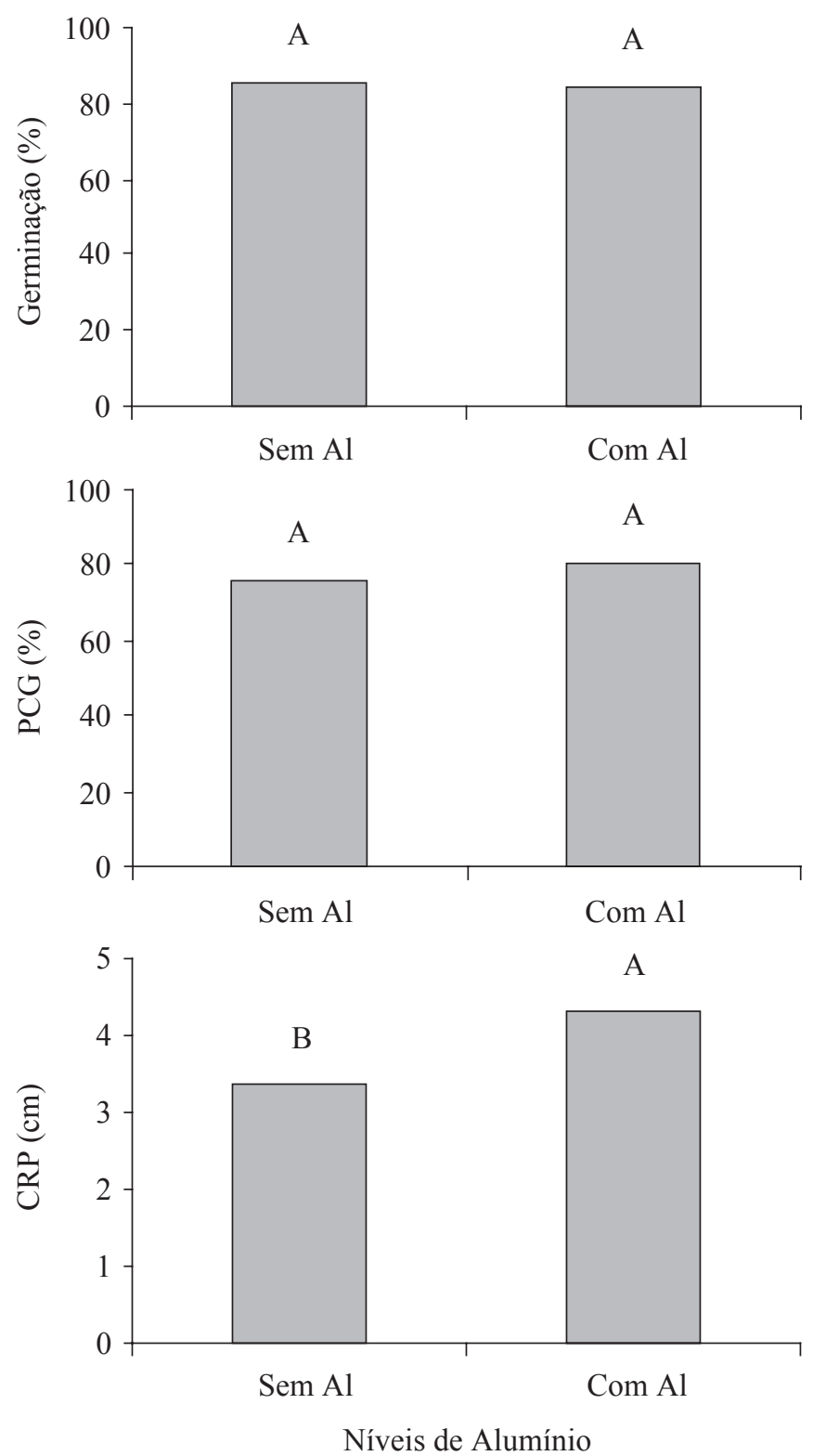

Figura 2. Germinação total, primeira contagem (PCG) de sementes e comprimento da raiz primária (CRP) de plântulas de café arábica na ausência e presença de alumínio. CCAUFES, Alegre, ES, 2006.

que produziu maior comprimento de raiz diferenciando-se, contudo do tratamento com ausência de alumínio.

De acordo com Epstein e Bloom (2006), frequentemente, fatores nutricionais influenciam o crescimento e a morfologia de órgãos particulares das plantas, de maneira específica. Como as raízes são os órgãos em contato mais estreito com o ambiente nutricional da planta, elas são especialmente propensas a serem afetadas por este ambiente. De acordo com Sivaguru e Horst (1998) o sítio primário da ação tóxica do alumínio é a parte distal da zona de transição no ápice das raízes, onde as células estão entrando em fase de alongamento. A inibição do crescimento da raiz é o sintoma visível mais rápido da toxicidade do $\mathrm{Al}$ em plantas (Degenhardt et al., 1998). Embora o Al possa ser tóxico e causar inibição da função vital dos elementos que se ligam a ele, como enzimas, calmodulina, ATP, GTP, DNA, ou outros processos metabólicos (Delhaize e Ryan, 1995), no presente trabalho não se verificou tal efeito. Possivelmente por ter penetrado somente no apoplasto, não atingindo o simplasto, onde poderia comprometer a função celular.

Em concentrações moderadas de $\mathrm{Al}$ tóxico, a inibição do crescimento celular é, provavelmente, o evento primário e a inibição da divisão celular é uma resposta aos efeitos sobre o crescimento celular, refletindo regulação interna dos processos de crescimento e desenvolvimento (Marschner, 2003).

Todas as cultivares apresentaram um aumento (de valores absolutos) no comprimento de raiz quando submetidas ao tratamento com alumínio, como pode ser observado na Tabela 1, que também evidencia a variação no comprimento das raízes, em porcentagem, em resposta às duas concentrações de alumínio. Esse percentual foi calculado com base na "razão da redução percentual no comprimento de raiz" $\{\% \mathrm{RCR}=[1-$ (Crescimento com Al / Crescimento sem Al)]x100\}(Cruz et al., 2004). Estes resultados corroboram as afirmações de Szymanska e Molas (1996), segundo os quais concentrações baixas de $\mathrm{Al}^{3+}$ podem estimular o desenvolvimento inicial do vegetal, sem causar efeito tóxico. Por outro lado, Konzak et al. (1976) citado por Braccini et al. (2000), verificaram que a concentração de $\mathrm{Al}$ requerida para produzir efeitos tóxicos em plântulas de soja, pela técnica de papel-solução, foi aproximadamente dez vezes maior que a utilizada em solução nutritiva. Esse aumento, dos valores absolutos, no comprimento da raiz primária sugere que a concentração de $45 \mathrm{mg} . \mathrm{L}^{-1}$ de $\mathrm{Al}^{3+}$ não é tóxico para as plântulas das quatro cultivares de café arábica.

Foy (1974) e Marschner (1986) citados por Veloso et al. (1995) discutem várias possibilidades de explicação que, em baixas concentrações, o Al possa, algumas vezes, induzir um aumento no crescimento ou produzir outros efeitos desejáveis, como aumento na disponibilidade do ferro em solo calcário (através da hidrólise do $\mathrm{Al}$ e da diminuição do $\mathrm{pH}$ ); correção ou prevenção de deficiência de ferro, pela liberação do ferro adsorvido em sítios metabolicamente inativos dentro da planta; bloqueia sítios, na parede celular, carregados negativamente, promovendo a absorção de fósforo; retardamento da deterioração das raízes em baixas 
Tabela 1. Comprimento da raiz primária de plântulas de 4 cultivares de café arábica e percentual de variação no comprimento das raízes, em resposta a duas concentrações de alumínio. CCA-UFES, Alegre, ES, 2006

\begin{tabular}{lccc}
\hline \multirow{2}{*}{ Cultivar } & \multicolumn{2}{c}{$\mathrm{Al}\left(\mathrm{mg} . \mathrm{L}^{-1}\right)$} & \multirow{2}{*}{ Variação } \\
\cline { 2 - 3 } & 0 & 45 & \\
\hline \multirow{2}{*}{ IAC 62 } & $------------\mathrm{cm}$----------- & $\%$ \\
IAPAR 59 & 3,98 & 4,00 & $+0,50$ \\
Obatã & 3,36 & 4,22 & $+25,60$ \\
Oeiras & 3,13 & 4,39 & $+37,06$ \\
\hline
\end{tabular}

concentrações de cálcio pelo crescimento mais lento; correção ou prevenção do efeito de concentrações excessivas de fósforo; prevenção de toxidez de cobre e manganês; redução do crescimento indesejável do topo de porta-enxerto rico em nitrogênio.

Szymanska e Molas (1996) não encontraram efeito do $\mathrm{Al}^{3+}$ na germinação de Cucumis sativus. Porém as concentrações de $\mathrm{Al}^{3+}$ influenciaram significativamente no crescimento. Em concentrações de 1 a $5 \mathrm{mg} \cdot \mathrm{dm}^{-3}$ de $\mathrm{Al}^{3+}$ o crescimento da plântula foi estimulado, não acarretando anormalidades morfológicas ou de desenvolvimento, todavia em concentrações de 20 a $40 \mathrm{mg} \cdot \mathrm{dm}^{-3}$ de $\mathrm{Al}^{3+}$ ocorreu inibição do crescimento de plântulas e danos nas mesmas.

Os escores das três primeiras variáveis canônicas relativas a cada cultivar estão agrupados na Tabela 2. A importância relativa de cada variável canônica é também dada pela razão entre a variância por ela explicada e o total da variância disponível. Uma vez que há nas primeiras variáveis a concentração de grande proporção da variância total, em geral referenciada como acima de $80 \%$, é viável o estudo da divergência genética por meio das distâncias geométricas entre progenitores em gráficos de dispersão, cujas coordenadas são escores relativos às primeiras variáveis canônicas (Cruz et al., 2004). A Tabela 2 evidencia que apenas as duas primeiras variáveis canônicas explicam cerca de $100 \%$ da variação total $(82,28 \%$ relativa à primeira, e $17,72 \%$ relativa à segunda). Assim, uma descrição concisa da divergência genética das cultivares pode ser feita utilizandose apenas essas duas variáveis. No entanto, a terceira variável passa a não ter importância, pois não responde por nenhuma porcentagem da dispersão total.

A Figura 3 representa a dispersão gráfica no espaço bidimensional das quatro cultivares em estudo, utilizando a primeira e a segunda variáveis canônicas. Verifica-se que a
Tabela 2. Escores das cultivares de café arábica em relação às três primeiras variáveis canônicas obtidas na avaliação da divergência genética. CCA-UFES, Alegre-ES, 2006

\begin{tabular}{lrcr}
\hline \multirow{2}{*}{ Cultivares } & \multicolumn{3}{c}{ Variável canônica } \\
& \multicolumn{1}{c}{$1^{\mathrm{a}}$} & $2^{\mathrm{a}}$ & \multicolumn{1}{c}{$3^{\mathrm{a}}$} \\
\hline Oeiras & 11,61 & 0,68 & 9,16 \\
Obatã & 11,68 & 1,86 & 9,17 \\
IAPAR 59 & 11,62 & 0,44 & 9,18 \\
C. Amarelo (IAC 62) & 8,96 & 1,02 & 9,17 \\
\hline Variância & 1,79 & 0,39 & 0,00 \\
Variância (\%) & 82,28 & 17,72 & 0,00 \\
Var. Acum. (\%) & 82,28 & 99,99 & 100,0 \\
\hline
\end{tabular}

cultivar Catuaí Amarelo (IAC 62) distancia-se nitidamente das demais, constituindo-se num grupo unitário bem característico. O segundo maior grau de divergência, que pode ser observado na Figura 3, foi encontrado entre as cultivares 1,2 e 3 , das quais a 1 e a 3 parecem ser as mais similares.

\section{CONCLUSÕES}

A germinação das sementes das cultivares de café arábica, Catuaí Amarelo IAC 62, Obatã, Oeiras e IAPAR 59, não é afetada pela concentração de $45 \mathrm{mg}$. $\mathrm{L}^{-1}$ de $\mathrm{Al}^{3+}$. A concentração de $45 \mathrm{mg} . \mathrm{L}^{-1}$ de $\mathrm{Al}^{3+}$ estimula o crescimento da raiz primária.

Existe considerável divergência genética entre as cultivares de café arábica em relação a sensibilidade ao aluminio na fase de germinação.

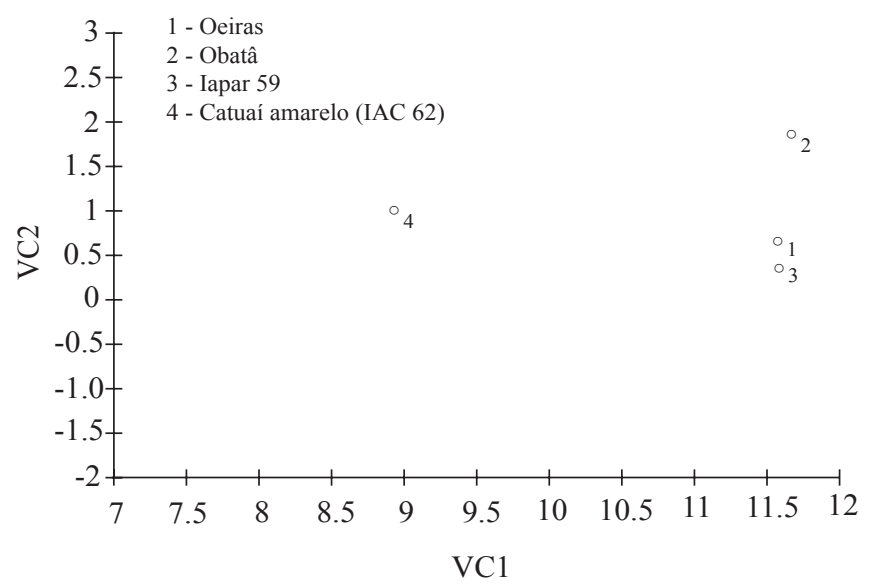

Figura 3. Dispersão de escores das quatro cultivares de café arábica em relação às duas primeiras variáveis canônicas $\left(\mathrm{VC}_{1} \mathrm{e} \mathrm{VC} \mathrm{VC}_{2}\right)$. CCA-UFES, Alegre-ES, 2006. 


\section{AGRADECIMENTOS}

Os autores agradecem à FAPES/CAPES pela concessão de bolsa de mestrado ao primeiro autor; ao $\mathrm{Eng}^{\circ}$ Agrônomo, Dr. Aymbiré Francisco de Almeida da Fonseca pela cessão de sementes e sugestões; ao Engo Agrônomo Dr. José Augusto Teixeira do Amaral, pelo apoio na execução inicial do experimento e ao Engo Agrônomo Dr. Frederico de Pina Matta pela valiosa contribuição na análise estatística.

\section{REFERÊNCIAS}

BRACCINI, A.L.; BRACCINI, M.C.L.; SCAPIM, C.A.; OLIVEIRA, V.R.; ANDRADE, C.A.B. Conservação de sementes de café-robusta (Coffea canephora Pierre ex Froehner) cultivar Conillon em função do grau de umidade e do tipo de embalagem. Revista Brasileira de Sementes, Brasília, v.20, n.2, p. 160-169, 1998 a.

BRACCINI, M.C.L.; MARTINEZ, H.E.P.; BRACCINI, A.L. Avaliação de linhagens de cafeeiros quanto à tolerância ao alumínio pelo método do papel-solução. Bragantia, Campinas, v.59, n.2, p.221-226, 2000.

BRACCINI, M.C.L.; MARTINEZ, H.E.P.; PEREIRA, P.R.G.; SAMPAIO, N.F.; SILVA, E.A.M. Tolerância de genótipos de cafeeiro ao $\mathrm{Al}$ em solução nutritiva. I. Crescimento e desenvolvimento da parte aérea e sistema radicular. Revista Brasileira de Ciência do Solo, Campinas, v.22, p.435-442, 1998 b.

BRAGANÇA, S.M.; FONSECA, A.F.A.; SARAIVA, J.S.T.; PEREIRA, J.O.; ROCHA, A.C.; PELISSARI, S.A.; BREGONCI, I.S. Formação de Mudas. In: COSTA, E.B. (Coord). Manual técnico para a cultura do café no estado do Espírito Santo. Vitória: SEAG-ES, 1995, p.19-28.

BRASIL. Ministério da Agricultura e Reforma Agrária. Regras para análise de sementes. Brasília: SNDA/DNDV/ CLAV, 1992. 365p.

CARVALHO, G.R.; PASQUAL, M.; GUIMARÃES, R.J.; MENDES, A.N.G.; BEARZOTTI, E.; FALCO, L. Efeito do tratamento de sementes na emergência e desenvolvimento de mudas de cafeeiro Coffea arabica L. Ciência e Agrotecnologia, Lavras, v.23, n.4, p.799-807, out./dez. 1999.

CASTRO, R.D.; ESTANISLAU, W.T.; MESQUITA, P.R.; HILHORST, H.W.M. A semente de café: desenvolvimento e perspectivas genômicas. In: SIMPÓSIO DE PESQUISA DOS CAFÉS DO BRASIL, 2, Vitória, 2001. Resumo. Brasília: Embrapa Café, 2001. p.27.

CBP\&D/Café-CONSÓRCIOBRASILEIRODEPESQUISA
E DESENVOLVIMENTO DO CAFÉ. Programa Nacional de Pesquisa e desenvolvimento do Café, Brasília, DF: 2004. 148p.

COSTA, P.S.C.; CARVALHO, M.L.M. Teste de condutividade elétrica individual na avaliação da qualidade fisiológica de sementes de café (Coffea arabica L.). Ciência e Agrotecnologia, Lavras, v.30, n.1, p.92-96, jan./fev. 2006.

CRUZ, C.D.; REGAZZI, A.J.; CARNEIRO, P.C.S. Modelos biométricos aplicados ao melhoramento genético. Viçosa: UFV, 2004. 480p.

CUSTÓDIO, C.C.; BOMFIM, D.C.; SATURNINO, S.M.; MACHADO NETO, N.B. Estresse por alumínio e por acidez em cultivares de soja. Scientia Agrícola, Piracicaba, v.59, n.1, p.145-153, 2002.

DEGENHARDT, J., LARSEN, P.B., HOWELL, S.H., KOCHIAN, L.V. Aluminum resistance in the Arabidopsis mutant alr-104 is caused by an aluminum-induced increase in rhizosphere pH. Plant Physiology, Minneapolis, v.117, p.19-27, 1998.

DELHAIZE, E.; RYAN, P.R. Aluminum toxicity and tolerance in plants. Plant Physiology, Minneapolis, v.107, n.2, p.315-321, 1995.

ELLIS, R.H.; HONG, T.D.; ROBERTS, E.H. An intermediate category of seed storage behavior?: I. Coffee. Journal of Experimental Botany, Oxford, v.41, n.230, p.1167-1174, 1990.

EPISTEIN, E.; BLOOM, A. Nutrição mineral de plantas: princípios e perspectivas. Londrina: Editora Planta, 2006. $403 p$.

FAGERIA, N.K. Otimização da eficiência nutricional na produção das culturas. Revista Brasileira de Engenharia Agrícola Ambiental, Campina Grande, v.2, p. 6-16, 1998.

FERRÃO, M.A.G.; FONSECA, A.F.A.; FERRÃO, R.G.; ROCHA, A.C. Cultivares de café arábica para a região das montanhas do estado do Espírito Santo. Vitória, ES: INCAPER, 2004, 38p.

FONSECA, A.F.A.; FERRÃO, M.A.G.; FERRÃO, R.G. A cultura do café robusta. In: SIMPÓSIO DE PESQUISAS DOS CAFÉS DO BRASIL, 1., 2000, Poços de Caldas. Palestras do I Simpósio de Pesquisa dos Cafés do Brasil, Brasília: Embrapa Café, 2002. p.119-145.

KING, M.W.; ROBERTS, E.H. The storage of recalcitrant seeds: achievements and possible approaches. Rome: International Board for Plant Genetic Resources, 1979. 96p.

KINRAIDE, T.B. Identity of the rhizotoxic aluminium species. Plant and Soil, Netherlands, v.134, p.167-178, 1991. 
KONRAD, M.L.F.; SILVA, J.A.B.; FURLANI, P.R.; MACHADO, E.C. Trocas gasosas e fluorescência da clorofila em seis cultivares de cafeeiro sob estresse de alumínio. Bragantia, Campinas, v.64, n.3, p.339-347, 2005.

LARCHER, W. Ecofisiologia Vegetal. São Paulo: Rima Artes e Textos, 2000. 531p.

LAZOF, D.B.; GOLDSMITH, J.G.; RUFTY, T.M.; LINTON, R.W. Rapid uptake of aluminum into cells of intact soybean root tips. A microanalytical study using secondary ion mass spectroscopy. Plant Physiology, Minneapolis, v.106, p.1107-1114, 1994.

MARSCHNER, H. Mineral nutrition of higher plants. $2^{\text {nd }}$ ed. London: Academic Press, 2003. 889p.

MASCARENHAS, H.A.A.; TANAKA, R.T.; WUTKE, E.B.; BRAGA, N.R.; MIRANDA, M.A.C. Alumínio e manganês no cultivo da soja em São Paulo. O Agronômico, Campinas, v.56, n.1, p.16-19, 2004.

McQUATTIE, C.J.; SCHIER, G.A. Response of red spruce seedlings to aluminum toxicity in nutrient solution: alterations in root anatomy. Canadian Journal of Forest Research, Ottawa, v.20, p.1001-1011, 1990.

MORAIS, O.P.; SILVA, J.C.; CRUZ, C.D.; REGAZZI, A.J.; NEVES, P.C.F. Divergência genética entre os genitores da população de arroz irrigado CNA-IRAT 4. Pesquisa Agropecuária Brasileira, Brasília, v.33, n.8, p.685-692, 1998.

PEREIRA, C.E.; PINHO, E.V.R.V.; OLIVEIRA, D.F.; KIKUTI, A.L.P. Determinação de inibidores da germinação no espermoderma de sementes de café (Coffea arabica L.). Revista Brasileira de Sementes, Brasília, v.24, n.1, p.306-311, 2002.

RENA, A.B.; MAESTRI, M. Fisiologia do cafeeiro. In: RENA, A.B.; MALAVOLTA, E.; ROCHA, M.; YAMADA, T. Cultura do Cafeeiro: fatores que afetam a produtividade. Piracicaba: POTAFÓS, 1986. p.13-85.
ROSA, S.V.F.; SANTOS, C.G.; PAIVA, R.; MELO, P.L.Q.; VEIGA, A.D.; VEIGA, A.D. Inibição do desenvolvimento in vitro de embriões de Coffea por cafeína exógena. Revista Brasileira de Sementes, Pelotas, v.28, n.3, p.177-184, 2006.

SAKIYAMA, N.S.; PEREIRA, A.A.; ZAMBOLIM, L. Melhoramento do Café Arábica. In: BORÉM, A. Melhoramento de espécies cultivadas. Viçosa: UFV, 1999. p.189-204.

SIVAGURO, M.; HORST, W.J. The distal part of the transitional zone is the most aluminum-sensitive apical root zone of maize. Plant Physiology, Minneapolis, v.163, p.155-163, 1998.

SZYMANSKA, M.; MOLAS, J. The effect of aluminium on early development stages of Cucumis sativus L. Folia Horticulturae, Poznañ, v.8, n.1, p.73- 83, 1996.

TEIXEIRA, T.D. Política estratégica para a cafeicultura brasileira. In: SIMPÓSIO DE PESQUISAS DOS CAFÉS DO BRASIL, 1., 2000, Poços de Caldas. Palestras do I Simpósio de Pesquisa dos Cafés do Brasil, Brasília: Embrapa Café, 2002. p.169-193.

TICE, K.R., PARKER, D.R., DeMASON, D.A. Operationally defined apoplastic and symplastic aluminum fractions in root tips of aluminum-intoxicated wheat. Plant Physiology, Minneapolis, v.100, p.309-318, 1992.

VELOSO, C.A.C.; MURAOKA, T.; MALAVOLTA, E.; CARVALHO, J.G. Efeito do alumínio em pimenteiras do reino (Piper nigrum L.) cultivadas em solução nutritiva. Scientia Agrícola, Piracicaba, v.52, n.2, p.368-375, 1995.

ZHAO, X.J.; SUCOFF, E.; STADELMANN, E.J. A13+ and $\mathrm{Ca} 2+$ alteration of membrane permeability of Quercus rubra root cortex cells. Plant Physiology, Minneapolis, v.83, p.159-162, 1987. 